\title{
ГЕОХИМИЧЕСКАЯ СПЕЦИФИКАЦИЯ ДОННЫХ ОТЛОЖЕНИЙ МАЛЬХ ОЗЕР УРБАНИЗИРОВАННЫХ РАЙОНОВ РЕСПУБЛИКИ КАРЕЛИИ
}

\section{Слуковский 3.И.}

Институт геологии КарНЦ РАН, Петрозаводск, slukovskii_z@igkrc.ru

Городская (урбанизированная) среда создает серьезные предпосылки для экологических рисков. Антропогенное влияние, оказываемое в городе на окружающую среду в первую очередь благодаря деятельности промышленных предприятий и транспорта, приводит к ухудшению состояния биоты, плоть до гибели отдельных видов и групп организмов. Тяжелые металлы являются одними из основных агентов негативного влияния техногенеза в пределах экосистем, затронутых урбанизацией. Регистрация экстремально высоких концентраций тяжелых металлов в почве, донных отложениях водных объектов и живых организмах городской среды иллюстрирует характер, интенсивность и диапазон воздействия тех или иных источников антропогенного воздействия, давая возможность для оценки экологических рисков на территории города.

Цель работы - провести общую оценку содержания микроэлементов, в том числе тяжелых металлов, в донных отложениях городских озер Республики Карелии, являющихся индикаторами состояния водосборных районов и появления экологических рисков на исследуемых территориях.

Исследование состояния урбанизированной среды проводилось на примере трех городов Республики Карелии (Петрозаводска, Медвежьегорска и Суоярви). В каждом из указанных населенных пунктов было исследовано эколого-геохимическое состояние донных отложений малых озер, расположенных в пределах городских территорий (рис. 1).

Отбор проб донных отложений проводится в 2016 и 2017 гг. в зимний и летний периоды. Для анализа был выбран слой озерных осадков до 30-60 см в зависимости от конкретного водного объекта. Методика отбора проб донных отложений и подготовки их к аналитическим исследованиям
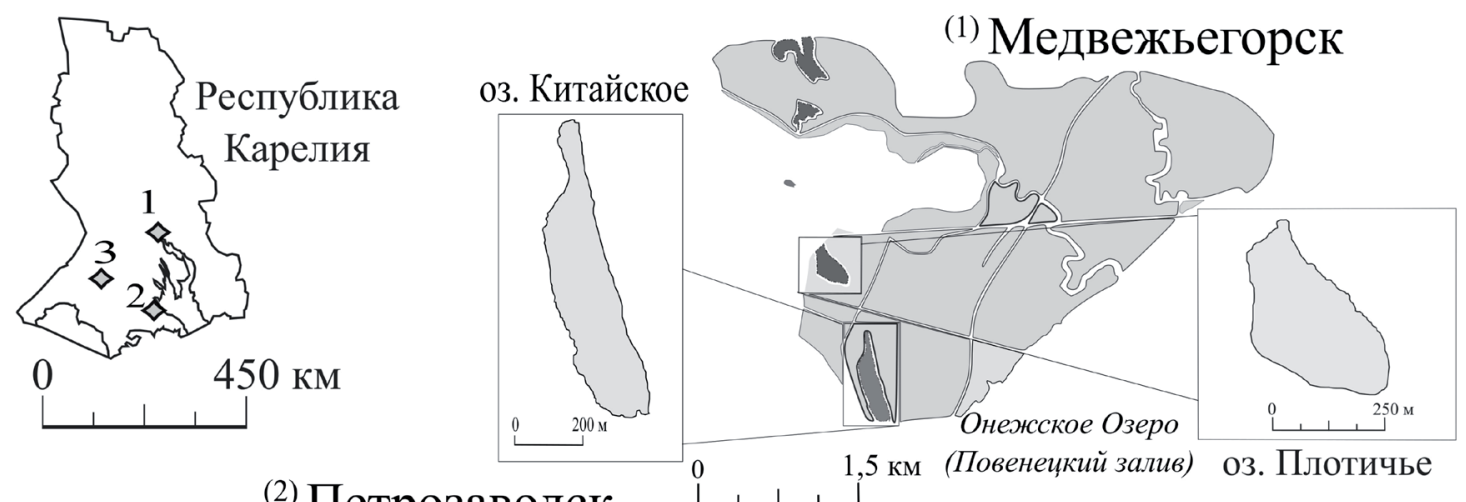

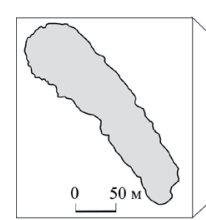

оз. Ламба

\section{${ }^{(2)}$ Петрозаводск}
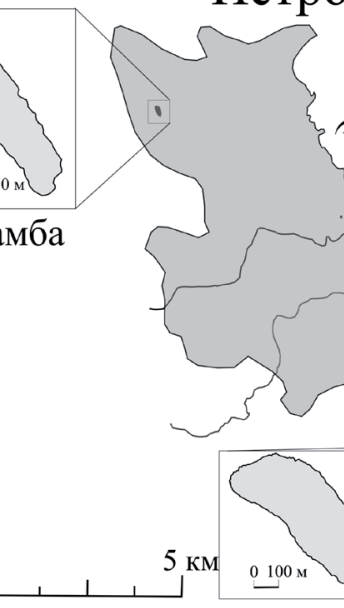
KM 1000

о3. Четырехверстное

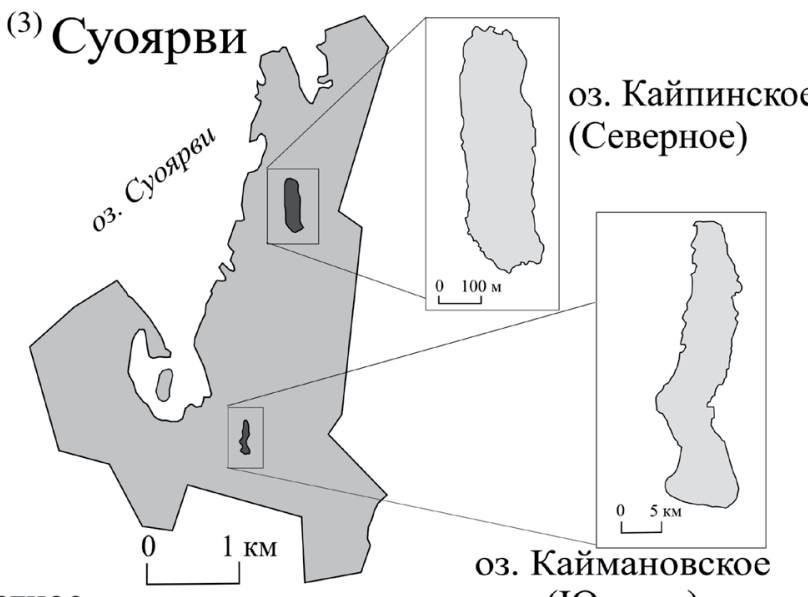

(Южное)

Рис. 1. Расположение объектов исследования. 


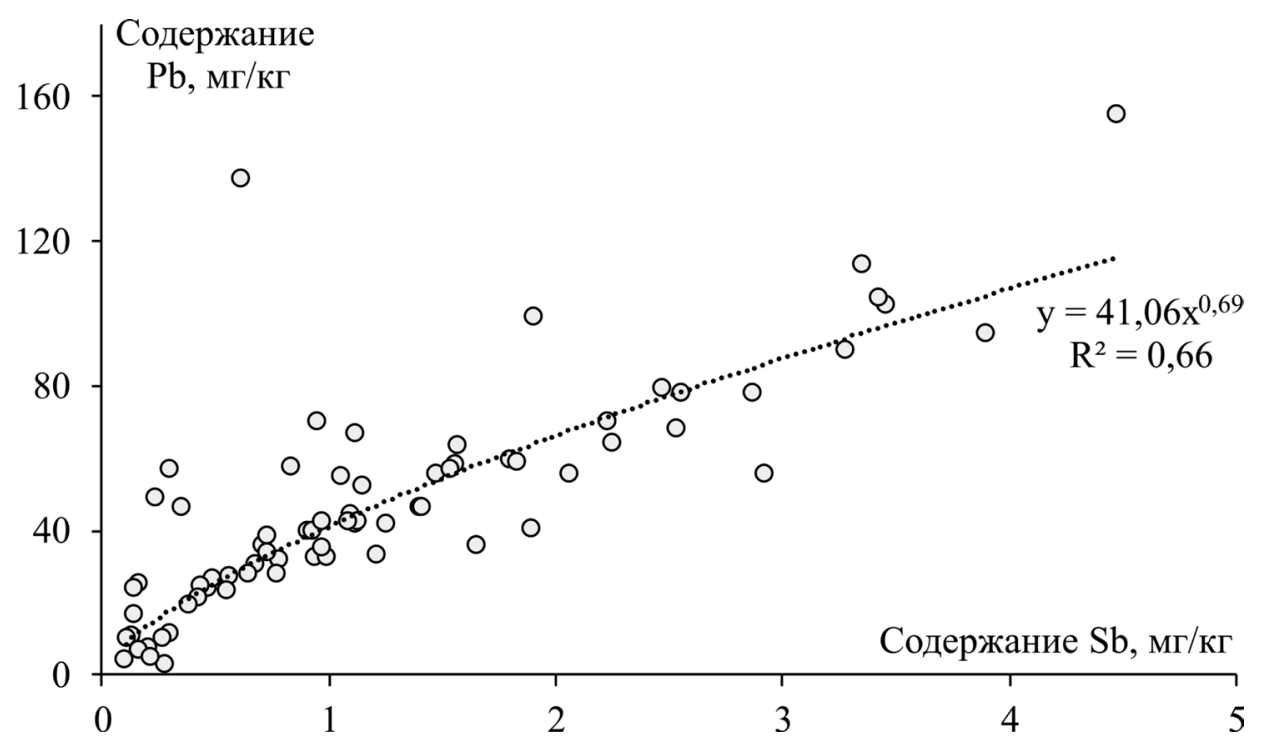

Рис. 2. Взаимосвязь концентраций $\mathrm{Pb}$ и $\mathrm{Sb}$ в озерных отложениях городской среды территории Республики Карелии.

описана в ранее проведенных работах $[5,6]$. Оценка микроэлементного состава донных отложений проведена при помощи масс-спектрометра с индуктивно связанной плазмой XSeries-2 ICP-MS на базе аналитического центра Института геологии КарНЦ РАН [4]. Формула геохимической ассоциации рассчитывалась согласно методическим указаниям [7].

Анализ изученных донных отложений городских малых озер Карелии показал, что все они относятся к сапропелям, наиболее распространенному типу пресноводных осадков региона [3]. Содержание микроэлементов в донных отложениях изученных урбанизированных водоемов позволило оценить мощность техногенно измененного слоя осадка в каждом озере. Минимальная мощность техногенно измененного слоя донных отложений была установлена для оз. Китайского, г. Медвежьегорск (16 см), а максимальная - для оз. Ламба, г. Петрозаводск (48 см).

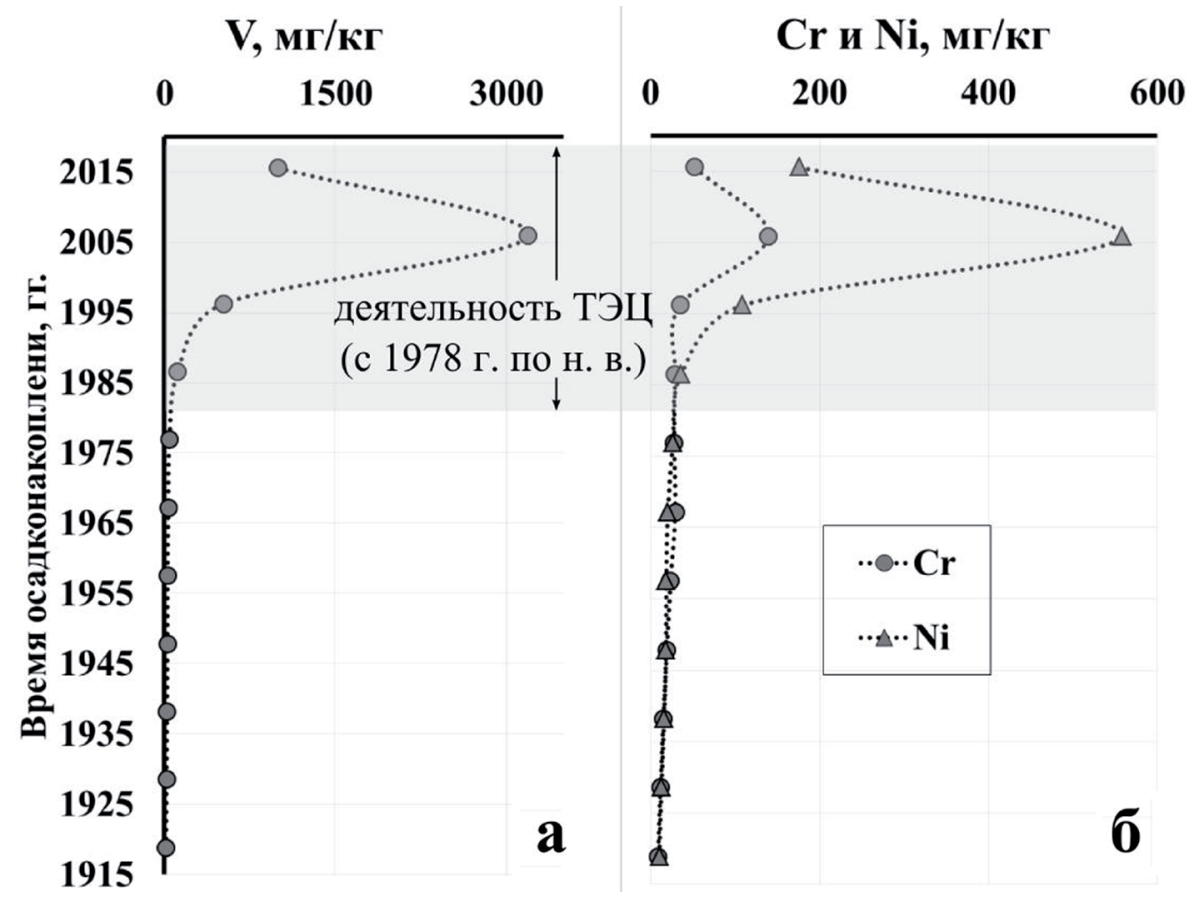

Рис. 3. Вертикальное распределение концентраций V (а) и Cr и Ni (б) в разрезе современных донных отложений оз. Ламба (г. Петрозаводск). 
Согласно формулам геохимических ассоциаций донных отложений исследованных городских озер (табл. 1) приоритетным загрязнителем для всех урбанизированных водоемов является $\mathrm{Pb}$. Концентрации этого элемента в верхних слоях озерных отложений многократно превышают условно-фоновый уровень для исследованных донных осадков (табл. 1). Наибольшие концентрации $\mathrm{Pb}$ установлены в отложениях оз. Ламба (Петрозаводск), оз. Кайпинское и оз. Каймановское (оба - Соуярви) и оз. Плотичье (Медвежьегорск).

Повышенный уровень свинцового загрязнения в донных отложениях изученных водоемов связан с фактором активного использования в 1940-80-е года по всему миру соединений $\mathrm{Pb}$ при изготовлении моторного топлива $[9,10]$, а также фактором трансграничного переноса этого элемента через атмосферу, что многократно отмечалось при изучении малых водоемов Севера России и сопредельных стран [2, 8].

При анализе химического состава донных отложений городских озер Карелии следует выделить повышенный уровень концентраций $\mathrm{Sb}$, известной своими токсичными свойствами по отношению к живым организмам. Кроме того, отмечается тесная связь между концентрациями $\mathrm{Pb}$ и $\mathrm{Sb}$ во всех техногенно измененных донных отложениях малых водоемов урбанизированной среды Карелии (рис. 2), что, вероятно, связано с содержанием Sb в тех пылевых выбросах, с которыми в водную среду региона поступал $\mathrm{Pb}$.

Таблица 1. Геохимические ассоциации в техногенно измененных донных отложениях водоемов урбанизированной среды Республики Карелии ( $\mathrm{Kc}$ - коэффициент концентрации, нижние индексы - величины коэффициентов концентрации для отдельно взятого элемента).

\begin{tabular}{|c|c|c|c|}
\hline \multirow{2}{*}{$\begin{array}{l}\text { Название } \\
\text { озера }\end{array}$} & \multicolumn{3}{|c|}{ Формула геохимической ассоциации донных отложений } \\
\hline & $\mathrm{K}_{\mathrm{c}} \geq 10$ & $10>K_{c} \geq 3$ & $3>\mathrm{K}_{\mathrm{c}} \geq 1,5$ \\
\hline Ламба & $\mathrm{Pb}_{21.1}-\mathrm{Sn}_{16.9}-\mathrm{V}_{16.6}$ & $\begin{array}{l}\mathrm{Sb}_{3.4}-\mathrm{Bi}_{5.6}-\mathrm{Ni}_{4.5}-\mathrm{Zn}_{4.4}-(\mathrm{Rb}- \\
\mathrm{Cu})_{4.3}-\mathrm{Ti}_{3.7}-\mathrm{Cs}_{3.6}-\mathrm{Ga}_{3.3}-(\mathrm{Ag}- \\
\mathrm{Li})_{3.1}-\mathrm{W}_{3.0}\end{array}$ & $\begin{array}{l}\mathrm{Nb}_{2.8}-\mathrm{Zr}_{2.6}-(\mathrm{Cd}-\mathrm{Rb})_{2.5}-(\mathrm{Mo}-\mathrm{Ta}- \\
\mathrm{Tl}_{2 . .4}-\mathrm{Cr}_{2.2}-\mathrm{Sr}_{2.1}-\mathrm{Co}_{2.0}-(\mathrm{Hf}-\mathrm{Sc})_{1.9}- \\
\mathrm{Ba}_{1.7}\end{array}$ \\
\hline Четырехверстное & - & $\mathrm{Pb}_{5.7}-\mathrm{Sb}_{4.3}-\mathrm{Sn}_{3.5}$ & $\begin{array}{l}(\mathrm{As}-\mathrm{Mn})_{2.9}-\mathrm{W}_{2.5}-(\mathrm{Rb}-\mathrm{Ti})_{2.2}-(\mathrm{Ga}- \\
\left.\mathrm{Li}-\mathrm{Zn})_{2.1}-\mathrm{Co}_{-}-\mathrm{Cr}-\mathrm{Cs}-\mathrm{Nb}-\mathrm{Ta}\right)_{2.0}^{-} \\
(\mathrm{Sr}-\mathrm{V})_{1.8}-\mathrm{Tl}_{1.7}-\mathrm{Bi}_{1.6}-\mathrm{Cu}_{1.5}\end{array}$ \\
\hline Плотичье & $\mathrm{Pb}_{10.2}$ & $\mathrm{Sb}_{9.8}-\mathrm{Zn}_{7.5}-\mathrm{Sn}_{6.6}-\mathrm{Cu}_{6.2}-\mathrm{P}_{6.0}-\mathrm{Cd}_{3.4}$ & $\begin{array}{l}\mathrm{Co}_{2.9}-(\mathrm{Bi}-\mathrm{V})_{2.7}-\mathrm{Cs}_{2.6}-\left(\mathrm{Mn}-\mathrm{Ni}_{2.2}-\right. \\
(\mathrm{As}-\mathrm{Cr}-\mathrm{Tl})_{2.0}-(\mathrm{Nb}-\mathrm{Th})_{1.7}-\mathrm{Ga}_{1.6} \\
\mathrm{Ta}_{1.5}\end{array}$ \\
\hline Китайское & - & $\begin{array}{l}\mathrm{Pb}_{6.4}-(\mathrm{Cd}-\mathrm{Sb})_{4.5}-\mathrm{Zn}_{3.3}-(\mathrm{Bi}- \\
\mathrm{Sn})_{3.0}\end{array}$ & $\begin{array}{l}(\mathrm{Mn}-\mathrm{P})_{2-5}-(\mathrm{Ta}-\mathrm{Tl}-\mathrm{U})_{2.0}-\mathrm{Rb}_{1.8}- \\
(\mathrm{Ga}-\mathrm{Li}-\mathrm{V})_{1.7}-(\mathrm{Ba}-\mathrm{Nb}-\mathrm{Cs})_{1.6}-\mathrm{Be}_{1.5}\end{array}$ \\
\hline $\begin{array}{l}\text { Кайпинское } \\
\text { (северное) }\end{array}$ & $\mathrm{Pb}_{17.7}$ & $\begin{array}{l}\mathrm{Sb}_{9.8}-\mathrm{Sn}_{5.9}-\mathrm{Cd}_{4.2}-\mathrm{Ag}_{3.9}-(\mathrm{As}- \\
\mathrm{Ba}_{3.6}-\mathrm{L}_{3.5}-\mathrm{Rb}_{3.2}-\left(\mathrm{Co}-\mathrm{Ti}_{3.1}{ }^{-}\right. \\
\mathrm{Zr}_{3.0}\end{array}$ & $\begin{array}{l}(\mathrm{Sr}-\mathrm{V})_{2.9}-(\mathrm{Zn}-\mathrm{Cs})_{2.8}-(\mathrm{Bi}-\mathrm{Hf})_{2.7}- \\
(\mathrm{Nb}-\mathrm{P})_{2.6}-\mathrm{Ga}_{2.4}-(\mathrm{Cu}-\mathrm{Tl}-\mathrm{U})_{2 .} \\
(\mathrm{Be}-\mathrm{W})_{{ }_{2.2}}-\mathrm{Th}_{2.1}-(\mathrm{Cr}-\mathrm{Ta})_{1.9}-\mathrm{Mn}_{1.8}- \\
\mathrm{Ni}_{1.6}-\mathrm{Sc}_{1.5}\end{array}$ \\
\hline $\begin{array}{l}\text { Каймановское } \\
\text { (южное) }\end{array}$ & $\mathrm{Sb}_{19.1}-\mathrm{Pb}_{18.4}$ & $\begin{array}{l}\mathrm{As}_{5.4}-\mathrm{Sn}_{4.6}-\mathrm{Zr}_{4.3}-(\mathrm{Cu}-\mathrm{Hf})_{4.1}- \\
\mathrm{Bi}_{3.9}-\mathrm{Li}_{3.8}-\mathrm{Rb}_{3.7}-(\mathrm{Nb}-\mathrm{Ti}-\mathrm{Tl})_{3.6}- \\
\mathrm{Ba}_{3.5}-(\mathrm{Cs}-\mathrm{U})_{3.4}-(\mathrm{Cd}-\mathrm{Ga})_{3.3}- \\
(\mathrm{Mo}-\mathrm{Ta}-\mathrm{Th}-\mathrm{V})_{3.0}\end{array}$ & $\begin{array}{l}(\mathrm{Be}-\mathrm{Co})_{2.8}-\mathrm{Cr}_{2.7}-\mathrm{W}_{2.6}-\mathrm{Ag}_{2.3}-\mathrm{Sr}_{2.2}- \\
\mathrm{Zn}_{2.0}-\mathrm{Sc}_{1.9}-\mathrm{P}_{1.6}\end{array}$ \\
\hline
\end{tabular}

Одним из главных загрязнителей оз. Ламба является $\mathrm{V}$ (табл. 1), чье поступление в водную среду связано с деятельностью Петрозаводской теплоцентрали (ТЭЦ), использовавшей и использующей до сих пор в качестве топлива мазут, в чьем составе обычно присутствуют $\mathrm{V}, \mathrm{Ni}, \mathrm{Cr}$ и другие химические элементы [1]. Переход на использование природного газа в начале 2000-х годов отразился на распределении $\mathrm{V}$ и сопутствующих ему микроэлементов в разрезе современных отложений оз. Ламба (рис. 3) [4].

Кроме описанных элементов экологические риски для биоты исследованных городских территорий могут быть связаны с воздействием $\mathrm{Cu}, \mathrm{Zn}, \mathrm{W}, \mathrm{Sr}, \mathrm{Co}, \mathrm{Mo}, \mathrm{As}, \mathrm{Mn}$ и $\mathrm{Tl}$ для г. Петрозаводска, 
с Cu, Zn, P, Co, Ni, Mn, As, Cr, Tl, U, V, Be для г. Медвежьегорска и с Cu, Zn, Sr, V, Bi, P, Tl, U, Be, $\mathrm{W}, \mathrm{Cr}, \mathrm{Mn}, \mathrm{Ni}, \mathrm{Co}$, As, Mo для г. Суоярви (табл. 1). Повышенные концентрации указанных химических элементов, в том числе, тяжелых металлов, могут оказывать воздействие на изменение структуры видового состава разного ранга водных организмов, на развитие заболеваемости у них, вплоть до гибели отдельных групп организмов, а также на биоаккумуляцию загрязнителей. Следует разработать специальные меры по предотвращению загрязнения малых водных объектов на территории городов Республики Карелии с учетом важности малых озер с точки зрения рекреации и бытового использования местным населением.

Автор выражает искреннюю благодарность своим коллегам А.С. Медведеву, Д.Г. Новицкому и Е.В. Сыроежко за всевозможное содействие в проведении совместных эколого-геохимических исследований.

Исследование выполнено при финансовой поддержке РФФИ в рамках научных проектов № 16-35-00026 и № 18-05-00897

\section{Литература}

1. Гоголашвили Э. Л., Гарифзянов А. Р. Проблемы анализа ванадия в сточных водах тепловых электростанций // Энергетика Татарстана. 2007. № 3. С. 60-63.

2. Даувальтер В. А. Халькофильные элементы ( $\mathrm{Hg}, \mathrm{Cd}, \mathrm{Pb}, \mathrm{As})$ в донных отложениях водных объектов водосбора Белого моря в пределах Кольского полуострова // Геохимия. 2006. № 2. 237-240. doi:10.1134/ S0097807810040093.

3. Синькевич Е.И., Экман И.М. Донные отложения озер Восточной части Фенноскандинавского кристаллического щита. Петрозаводск: Карельский научный центр РАН. 1995. 177 с.

4. Слуковский 3.И., Ильмаст Н.В., Суховская И.В., Борвинская Е.В., Гоголев М.А. Геохимическая специфика процесса современного осадконакопления в условиях техногенеза (на примере оз. Ламба, Петрозаводск, Карелия) // Труды Карельского научного центра РАН. 2017. № 10. С. 45-63.

5. Слуковский 3.И., Медведев А.С. Содержание тяжелых металлов и мышьяка в донных отложениях озер Четырехверстного и Ламба (г. Петрозаводск, Республика Карелия) // Экологическая химия. 2015. № 1. С. 56-62.

6. Слуковский 3.И., Медведев А.С., Бубнова Т.П., Сыроежко Е.В. Накопление и вертикальное распределение тяжелых металлов в сапропеле озера Грязное (Медвежьегорский район, Республика Карелия) // Вестник МГТУ 2017. Т. 20, № 1/2. С. 177-188. DOI: 10.21443/1560-9278-2017-20-1/2-177-188.

7. Янин Е.П. Техногенные геохимические ассоциации в донных отложениях малых рек агроландшафтов (формирование, состав, экологическая оценка) // Теоретическая и прикладная экология. 2009. № 1. С. 66-71.

8. Keinonen M. The isotopic composition of lead in man and the environment in Finland 1966-1987: isotope ratios of lead as indicators of pollutant source // The Science of the Total Environment. 1992. V. 113, No 3. P. 251-268. doi:10.1016/0048-9697(92)90004-C.

9. McConnell, J. R., Edwards, R. Coal burning leaves toxic heavy metal legacy in the Arctic. Proceedings of the National Academy of Sciences. 2008. V.34. P. 12140-12144.

10. Thomas V. M. The elimination of lead in gasoline // Annual Review of Energy and the Environment. 1995. V. 20. P. 301-324. 